\title{
REPORTS OF BRAZILIAN FEDERAL MEAT INSPECTION SYSTEM IN SWINE SLAUGHTERHOUSES
}

\author{
Arlei Coldebella ${ }^{1}$, Jalusa Deon Kich ${ }^{1}$, Elenita Ruttscheidt Albuquerque ${ }^{2}$, \\ Ricardo José Buosi ${ }^{2}$

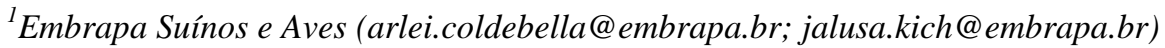 \\ ${ }^{2}$ Ministério da Agricultura Pecuária e Abastecimento (elenita.albuquerque@agricultura.gov.br; \\ ricardo.buosi@agricultura.gov.br)
}

\begin{abstract}
In the last decades the pig production improvement had impacted on zoonotic profile attributed to pork. This fact has created a need to modernize the meat inspection system traditionally applied, driving the focus to risks that really threaten food safety nowadays. This modernization is a trend in meat producer countries and European Union is ahead in this process. In this way, Brazil is assessing the new systems and building an own proposal which has been conducted under a national project linked by many coordinated actions. The first step of this work is to analyze the data of current inspection system. Then, the aim of this study is to evaluate the carcasses and viscera disposition reported by Brazilian Federal Meat Inspection. The analyzed database encompasses the reports of 114 slaughterhouses recorded from 2012 to 2014 into SIGSIF platform. The results were summarized by descriptive statistics on tables and figures using the SAS software. It was possible to show that the major "post mortem" causes of carcass/viscera trimming or condemnation were resulted from production diseases, as adherences $(3.72 \%)$, pleurisy $(0.85 \%)$, abscess $(0.58 \%)$ and pneumonia $(0.20 \%)$. Likewise for industrial process problems, as carcass contamination by evisceration leaking (1.8\%) and traumatic lesions (1.57\%). Zoonosis injuries condemnations were reported in very low frequency in a few slaughterhouses, usually once. Among the total of organs and carcass inspected, cysticercosis was registered in just $0.00092 \%$ in 25 slaughterhouses, endocarditis in $0.00193 \%$ (23 slaughterhouses), erysipelas in $0.0045 \%$ (38 slaughterhouses), sarcosporidiosis in $0.00051 \%$ (17 slaughterhouses) and tuberculosis in $0.000046 \%$ (12 slaughterhouses). Thus, the current meat inspection system is prepared to detect zoonosis that no longer occur or happen in very low frequency. In the other hand, the traditional ante and post mortem inspection methodologies are not able to detect the main current foodborne pathogens globally distributed as Salmonella.
\end{abstract}

\section{Introduction}

In the last decades the pig production improvement had impacted on zoonotic profile attributed to pork. This fact has created a need to modernize the meat inspection system traditionally applied, driving the focus to risks that really threaten food safety nowadays. This modernization is a trend in meat producer countries and European Union is ahead in this process.

In this way, Brazil is assessing the new systems and building an own proposal which has been conducted under a national project linked by many coordinated actions. The first step of this work is to analyze the data of current inspection system. 
Then, the aim of this study is to evaluate the carcasses and viscera disposition reported by Brazilian Federal Meat Inspection.

\section{Material and methods}

Brazilian Federal Meat Inspection maintains and manages an Information System named SIGSIF, which allows recording a wide variety of data about slaughter, condemnation and trimming. Initially, data from 117 Federal Inspected swine slaughterhouses, with approximately 97.2 million pigs slaughtered from 2012 to 2014 were obtained from two Excel spreadsheets extracted from SIGSIF platform. One of them contained the data of total monthly slaughter by species and animal category and another containing the causes of condemnation or trimming per inspection line and respective quantities.

SAS software (2012) was used to make an exploratory statistical analysis aiming to evaluate the data consistence and to ensure the results robustness. Assisted by Federal Meat Inspection Service the analysis has started detecting and correcting (if possible) inconsistencies in the database, if the correction was not possible the data were discarded.

After the initial exploratory analysis the database encompasses the reports of 114 slaughterhouses $(94,262,328$ slaughtered pigs) recorded from 2012 to 2014 into SIGSIF platform. The results were summarized by descriptive statistics on tables and figures using the SAS software.

\section{Results and discussion}

The Brazilian condemnation/trimming in pigs slaughter for all causes is depicted in Figure 1 that shows the major percentages of condemnation/trimming, for example: $31.53 \%$ of the lungs, $15.24 \%$ of livers, $14.44 \%$ of kidneys and $10.2 \%$ of carcass. Contamination by evisceration leaking and other sources was one of the most important causes of condemnation/trimming, representing more than $60 \%$ of the causes for spleen, head, stomach, intestine and tongue. For carcass this cause represents $1.797 \%$ of the total of slaughtered pigs and approximately $18 \%$ of the all causes of condemnation/ trimming.

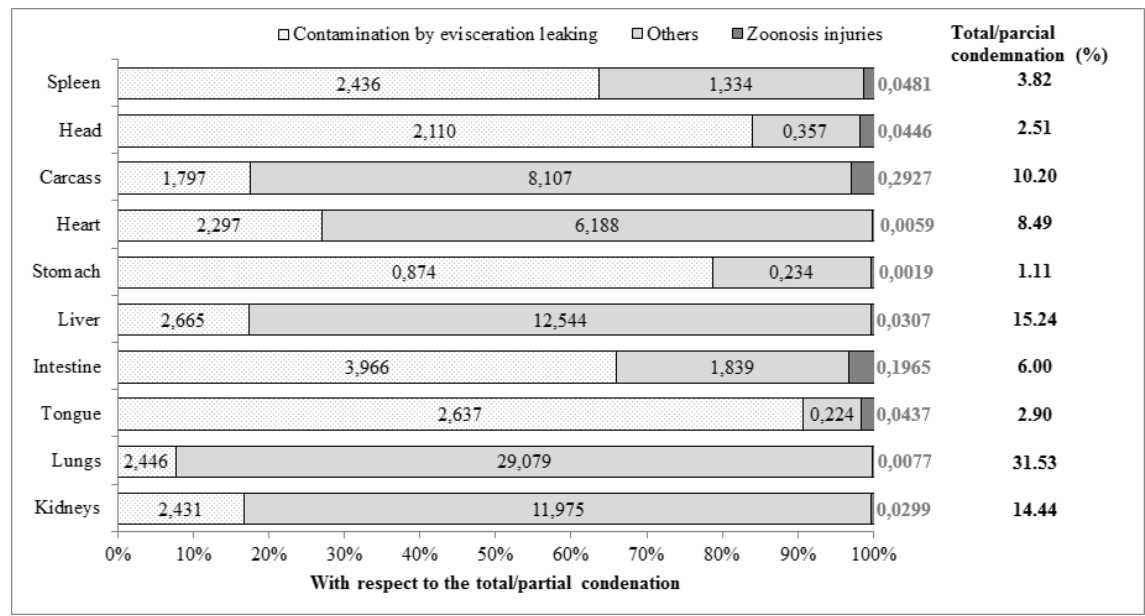

Figure 1. Percentage of total/partial condemnation by all causes and the contribution of contamination by evisceration leaking and zoonosis lesions in function to the body part. 
By the other hand, zoonosis associated condemnations were reported in very low frequency, in a few slaughterhouses, usually once. Lymphadenitis is an exception in this context and represents the majority of this kind of condemnation, with $0.81 \%$ of the total of organs and carcass inspected (99\% of all zoonosis associated lesions recorded), and $0.29 \%$ of the carcasses (Table 1). Among the total of organs and carcass inspected in others zoonosis associated lesions, erysipelas was recorded in just $0.0045 \%$ (38 slaughterhouses), endocarditis in $0.00193 \%$ (23 slaughterhouses), cysticercosis in $0.00092 \%$ (25 slaughterhouses), sarcosporidiosis in $0.00051 \%$ (17 slaughterhouses) and tuberculosis in $0.000046 \%$ (12 slaughterhouses).

It was possible to show that the major "post mortem" causes of carcass/viscera trimming or condemnation were resulted from production diseases, as adherences $(3.72 \%)$, pleurisy $(0.85 \%)$, abscess $(0.58 \%)$ and pneumonia $(0.20 \%)$. Likewise for industrial process problems, as carcass contamination by evisceration leaking $(1.8 \%)$ and traumatic lesions $(1.57 \%)$ (Figure 2).

Table 1. Quantity of zoonosis associated lesions condemnations reported among the total of organs and carcass inspected.

\begin{tabular}{lrccr}
\hline Zoonosis & \multicolumn{1}{c}{$\begin{array}{c}\text { Total } \\
\text { condemnation }\end{array}$} & $\begin{array}{c}\text { Number of positive } \\
\text { slaughterhouses }\end{array}$ & $\begin{array}{c}\text { Main body part } \\
\text { condemned }\end{array}$ & $\begin{array}{c}\text { Total condemnation } \\
\text { on main body part }\end{array}$ \\
\hline Cysticercosis & $869(0.00092 \%)$ & 25 & Heart & $668(0.00071 \%)$ \\
Endocarditis & $1,815(0.00193 \%)$ & 23 & Carcass & $837(0.00089 \%)$ \\
Erysipelas & $4,269(0.0045 \%)$ & 38 & Carcass & $808(0.00086 \%)$ \\
Lymphadenitis & $760,643(0.8069 \%)$ & 75 & Carcass & $273,686(0.2903 \%)$ \\
Sarcosporidiosis & $482(0.00051 \%)$ & 17 & Carcass & $476(0.00051 \%)$ \\
Tuberculosis & $43(0.000046 \%)$ & 12 & Carcass & $22(0.000022 \%)$ \\
\hline
\end{tabular}

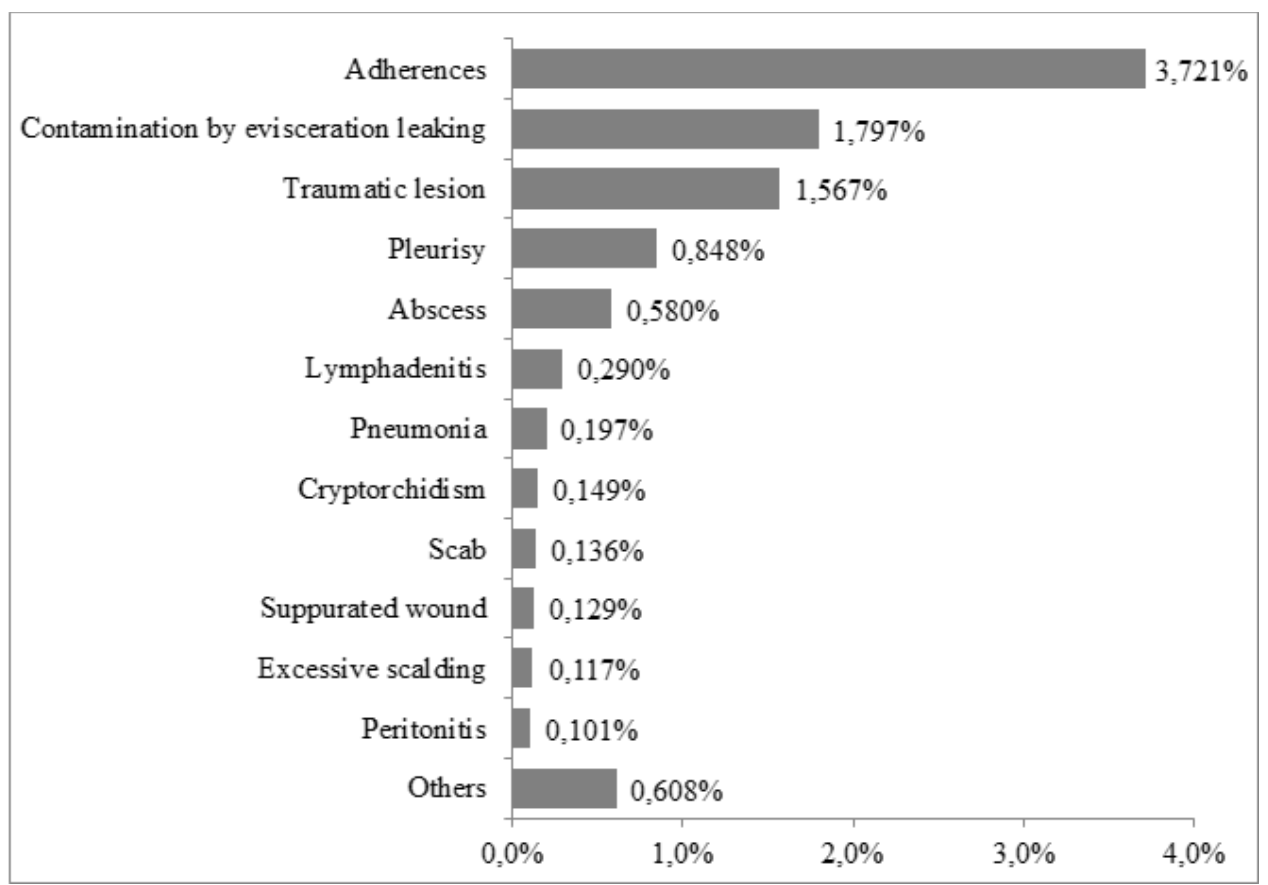

Figure 2. Main causes of carcass condemnations/trimming in pigs slaughtered in the Brazil from 2012 and 2014. 
Back to the forties, Ribeiro (1951) reported that the principal cause of condemnation was tuberculosis follow by cysticercosis, that produce lesions easily detectable by the meat inspection service. This dramatic decline in both diagnosis to negligenciable level is a consist result of all systematic improvement in the Brazilian pig production chain. The worldwide evolution in biosecurity and good practices in pig farming has shifted the zoonotic profile attributed to pork. In face of that is necessary to adapt the meat inspection procedures to allow the detection of the current hazards in order to mitigate them.

Brazilian results are comparable to those obtained in Europe Community that, after an extensive study, changed the meat inspection procedures in 2014 (Official Journal of the European Union, 2014). EFSA (2011) had purposed that "risk reduction measures at slaughterhouse level are focused on prevention of microbial contamination through technology- and process hygiene-based measures (Good Manufacturing Practices (GMP)/Good Hygienic Practices (GHP) and Hazard Analysis and Critical Control Points (HACCP)), including omitting palpation/incision during post-mortem inspection in routine slaughter, as well as hazard reduction/inactivation meat treatments if necessary. At farm level, risk reduction measures are based on herd health programs, closed breeding pyramids and Hygienic Practices and Good Framing Practices”.

Therefore, considering the role of meat business for Brazil is urgent to modernize many aspects of meat inspection system applied nowadays. These results are the base for a risk assessment study in order to identify the most relevant biological hazards in the context of Brazilian pork inspection. Wide studies nationally coordinated should be conducted to found out the real risks associated to specific country features. Differences in food animal production chain organization may result in distinct hazards. Furthermore, is essential to specify the production conditions that the modernized inspection procedures will be applied.

\section{Conclusion}

The current meat inspection system is not able to detect the main current foodborne pathogens globally distributed as Salmonella. Although the traditional ante and post mortem inspection methodologies was presented some effectiveness in detect zoonosis that happen in very low frequency, some of these procedures are intended to search for diseases that no longer occurs.

\section{References}

EFSA. Scientific Opinion on the public health hazards to be covered by inspection of meat (swine). EFSA Journal 2011;9(10):2351 [198 pp.].

Official Journal of the European Union, 2014 Commission Regulation (EU) No 218/2014 of 7 March 2014.

RIBEIRO, P. A. Causes of Swine Rejection in Slaugtherhouses of Central Brasil from 1936 to 1949. Revista da Faculdade de Medicina Veterinária de São Paulo. V.4, F. 3, 1951. (in Portuguese).

SAS INSTITUTE INC. System for Microsoft Windows, Release 9.4, Cary, NC, USA, 2002-2012. (cdrom). 